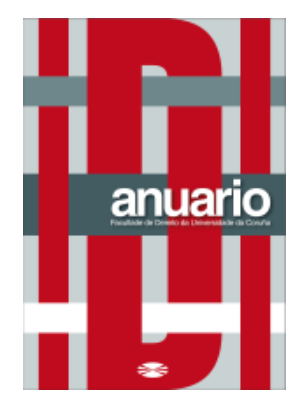

Anuario da Facultade de Dereito da Universidade da

Coruña Vol. 22 (2018), pp. 447-462

ISSNe: 2530-6324 || ISSN: 1138-039X

DOI: https://doi.org/10.17979/afdudc.2018.22.0.5196

\title{
COMENTARIO A LA SENTENCIA DEL TRIBUNAL CONSTITUCIONAL 157/2017, DE DECLARACIÓN DE INCONSTITUCIONALIDAD SOBRE LA MEDIDA “ANTI- TRANSFUGUISMO” DE LA LEY ELECTORAL
}

\author{
JUAN FRANCISCO SÁNCHEZ GONZÁLEZ \\ Doctor en Derecho, Universidad de A Coruña.
}

\begin{abstract}
Resumen: A través del artículo que se presenta analizaremos la Sentencia del Tribunal constitucional 157/2017, de 21 de diciembre, por la que se declara inconstitucional y nulo el párrafo tercero del art. 197.1 a) de la Ley Orgánica 5/1985, de 19 de junio, de Régimen electoral general, a partir del estudio del fenómeno del transfuguismo, el contexto del supuesto particular que resuelva el Tribunal y su extensión a los planteamientos jurisprudenciales que se han sucedido desde la reforma, con una aproximación a la significación y alcance del derecho fundamental a la participación política y su afectación en el nuevo escenario político que plantea la Sentencia dictada.
\end{abstract}

Palabras clave: Derecho a la participación política, Tribunal Constitucional, Ley Orgánica 5/1985 de Régimen electoral general, transfuguismo.

\footnotetext{
Abstract: Through this paper we will analyze the judgement of the Constitutional Court $157 / 2017$, of 21 December, by which declares unconstitutional and null the third paragraph of the article 197.1 a) of the Organic Law 5/1985, of 19 of June, of electoral system General, from the study of the phenomenon of transfugueism, the context of the particular assumption that the Tribunal solves and its extension to the jurisprudence approaches that have occurred since the reform, with an approximation to the significance and scope of the fundamental right to political participation and its affectation in the new political scenario that raises the sentence dictated.
} 
Keywords: Right to political participation, Constitutional Court, Organic Law 5/1985 on the General Electoral System, transfusion.

SUMARIO: I.- INTRODUCCIÓN: EN RECUERDO DEL TRANSFUGUISMO II.LOS ANTECEDENTES DEL CASO III.- EL DERECHO A LA PARTICIPACIÓN POLÍTICA IV.- EL ALCANCE DE LA MEDIDA “ANTITRANSFUGUISMO” V.- LA SENTENCIA DEL TRIBUNAL CONSTITUCIONAL VI.- CONCLUSIÓN

\section{I.- INTRODUCCIÓN: EN RECUERDO DEL TRANSFUGUISMO}

Será objeto de análisis a través de este artículo la Sentencia del Tribunal constitucional 157/2017, de 21 de diciembre, por la que se declara inconstitucional y nulo el párrafo tercero del art. 197.1 a) de la Ley Orgánica 5/1985, de 19 de junio, de régimen electoral general, en la redacción dada por la Ley Orgánica 2/2011, de 28 de enero.

Antes de proceder a efectuar dicha valoración convendría recordar un fenómeno que habría desaparecido de nuestro entorno local, cuál es el referido al "transfuguismo".

En el año 2011, quién suscribe tuvo oportunidad de publicar un artículo donde se evidenciaba la necesidad de adoptar medidas contra el fenómeno calificado de "transfugismo".

La Comisión de seguimiento del Acuerdo sobre el Código de Conducta Política en relación con el transfuguismo en las Corporaciones Locales había estudiado hasta 2010, 613 denuncias, declarando 204 casos de transfuguismo ${ }^{1}$.

El término transfuguismo es realmente ambiguo y nada fácil de precisar su significado, de manera que nuestro primer objetivo será recordar su definición al objeto de esclarecer su interpretación más correcta, ahora que debemos volver a la regulación anterior una vez que el Tribunal Constitucional ha venido a declarar inconstitucional la modificación que agravaba la mayoría necesaria para presentar una moción de censura.

En consecuencia, la referencia que nos podrá ilustrar será el Acuerdo sobre el Código de Conducta Política en relación con el transfuguismo en las Corporaciones Locales en su II Addenda del 2006, que establece:

\footnotetext{
${ }^{1}$ Cfr. SÁNCHEZ GONZÁLEZ, J.F., El juego de la democracia. El Consultor de los Ayuntamientos y juzgados, № 8, Sección Colaboraciones, Quincena del 30 Abr. al 14 May. 2011, pág. 1007-1023.
} 
«Primero.- A los efectos del presente Acuerdo, se entiende por tránsfugas a los representantes locales que, traicionando a sus compañeros de lista y/o de grupo - manteniendo estos últimos su lealtad con la formación política que los presentó en las correspondientes elecciones locales-, o apartándose individualmente o en grupo del criterio fijado por los órganos competentes de las formaciones políticas que los han presentado, o habiendo sido expulsados de éstas, pactan con otras fuerzas para cambiar o mantener la mayoría gobernante en una entidad local, o bien dificultan o hacen imposible a dicha mayoría el gobierno de la entidad. Cuando surgiesen dudas sobre qué miembros de una lista y/o grupo político han incurrido en transfuguismo, será la formación política que los ha presentado la que deberá aclarar por escrito cuáles de ellos se han apartado de la disciplina de partido, a efectos de su calificación como tránsfugas. Las medidas previstas en este Acuerdo con respecto a los tránsfugas, serán igualmente de aplicación a aquellos miembros de las entidades locales que se beneficien de su conducta»² .

Recuperado de nuevo el olvidado concepto de tránsfuga en el marco de la continuidad del gobierno de una Institución Pública y las consecuencias nocivas para la democracia de la actitud de aquellos que concurriendo en las elecciones bajo las siglas de un grupo político, engañan a sus electores y deciden apartarse de su criterio, esconde, sin embargo, este fenómeno una problemática más compleja que guarda una conexión sustancial con el régimen constitucional del ejercicio del mandato político.

En nuestra Constitución se contempla un precepto esencial que, anticipamos, ha sido valorado por el Tribunal Constitucional en su decisión, por polémica que pueda parecer, resucitando el fenómeno del transfuguismo y planteando un escenario complejo para futuras elecciones.

Nos referimos, pues, al concepto de participación política que maneja la Constitución en su artículo 23 y que ha interpretado el Tribunal Constitucional como elemento que se vulnera en la regulación incorporada en el artículo 197.1.a) de la Ley Orgánica de régimen electoral general.

\section{II.- LOS ANTECEDENTES DEL CASO}

El pronunciamiento del Tribunal Constitucional trae causa de la cuestión de inconstitucionalidad planteada por el Tribunal Superior de Justicia de Canarias, quién consideró, respecto del art. 197.1 a), párrafo tercero en relación con el párrafo segundo, de la Ley Orgánica 5/1985, de 19 de junio, de régimen electoral general, que podría estar vulnerando el derecho fundamental contemplado en el artículo 23.2 de la Constitución.

\footnotetext{
${ }^{2}$ Cfr. Acuerdo sobre el Código de Conducta Política en relación con el transfuguismo en las Corporaciones Locales, II Addenda, Ministerio de Administraciones Públicas, 2006.
} 
Resulta interesante destacar el auto por el que se acuerda plantear cuestión de inconstitucionalidad que lleva fecha de 31 de julio de 2014, resolviendo el Tribunal Constitucional el 27 de diciembre de 2017, en una demora de casi tres años y medio.

El supuesto de hecho se inicia tras las elecciones locales celebradas el día 22 de mayo de 2011 y, en particular, lo sucesos que tuvieron lugar en el Ayuntamiento de Tacoronte (Tenerife). Ayuntamiento que celebró sesión constitutiva el 11 de junio de 2011, prestando juramento los concejales electos y resultando proclamado como AlcaldePresidente de la Corporación local don Álvaro Agustín Dávila González, que habría obtenido trece votos favorables del total de los veintiún miembros electos.

De conformidad con lo dispuesto en el art. 24 del Real Decreto 2568/1986, de 28 de noviembre, por el que se aprueba el Reglamento de organización, funcionamiento y régimen jurídico de las Entidades locales, las formaciones políticas que obtuvieron representación comunicaron la constitución de cuatro grupos políticos: Coalición CanariaPNC (siete miembros); Grupo Popular y Grupo Socialista (cada uno de ellos con seis) y Alternativa sí se puede por Tenerife (Grupo Municipal Mixto: dos concejales).

El día 9 de octubre de 2013, once concejales del Ayuntamiento (todos los del Grupo Popular y cinco de los seis pertenecientes al Grupo Socialista) presentaron una moción de censura contra el Alcalde don Álvaro Agustín Dávila González (Coalición CanariaPNC) y apoyaron otra candidatura firmada por todos ellos y encabezada por uno de los concejales socialistas, don Rodolfo León Martín.

El día 11 de octubre de 2013, el único concejal socialista no firmante, don Carlos Medina Dorta, solicitó a la Secretaría General de la Corporación que certificara si los restantes miembros del Grupo Socialista habían retirado su apoyo a la moción de censura.

En la misma fecha, el Secretario de Organización del PSOE-Canarias comunicó a la Secretaría General del Ayuntamiento la expulsión provisional del partido de los concejales socialistas firmantes de la moción, señalando que el Grupo Municipal Socialista quedaría compuesto exclusivamente por don Carlos Medina Dorta.

Adjuntaba a dicha comunicación las resoluciones del PSOE que así lo acordaban. Las expulsiones provisionales, con apertura asociada de expediente disciplinario, se justificaban en que la moción de censura suponía un incumplimiento del Acuerdo alcanzado en Canarias, entre el PSOE y Coalición Canaria, para constituir gobiernos de coalición en las instituciones autonómicas, insulares y municipales; en la falta de autorización de los órganos competentes del partido político para la presentación de la moción de censura y en la desatención del requerimiento que se efectuó a los firmantes por la Comisión 
Ejecutiva Regional del PSC-PSOE en orden a la retirada de aquélla antes de las 10 horas del día 11 de octubre.

El día 18 de octubre de 2013 se comunicó a la Secretaría General de la Corporación la expulsión definitiva del partido político de los cinco concejales del Grupo Municipal Socialista firmantes de la moción, acordada por resoluciones de esa misma fecha de la Comisión Ejecutiva Federal del PSOE, reiterándose la nueva composición del Grupo Municipal (integrado por el concejal restante).

A la vista de la normativa a la fecha se procedió a la convocatoria automática de la sesión, que procedió a la aprobación de la moción de censura el día 22 de octubre de 2013, con once votos a favor, ocho en contra y dos abstenciones, proclamándose Alcalde al candidato propuesto, don Rodolfo León Martín.

Don Álvaro Agustín Dávila González, invocando la vulneración del art. 23.2 de la Constitución, interpuso recurso contencioso-administrativo por el procedimiento especial de protección de derechos fundamentales contra los Acuerdos adoptados el día 22 de octubre de 2013 por la Mesa de edad y el Pleno del Ayuntamiento de Tacoronte, en virtud de los cuales se dispuso la tramitación, sometimiento a votación y aprobación de la moción de censura presentada, que conllevó su destitución y la designación de nuevo Alcalde en la persona de don Rodolfo León Martín.

La demanda se basaba en el incumplimiento de las exigencias de mayoría reforzada del art. 197.1 a), párrafo tercero, de la Ley Orgánica 5/1985, y en la no verificación de dicha mayoría por la Mesa de edad, según dispone el apartado e) del mismo precepto, en la redacción dada a ambas letras por la Ley Orgánica 2/2011, de 28 de enero.

La hipótesis de vulneración se planteaba en términos claros, puesto que, según el precepto invocado, la mayoría absoluta se debería incrementar en la medida en que "alguno de los concejales proponentes de la moción hay a dejado de pertenecer, por cualquier causa, al grupo político municipal al que se adscribió al inicio de su mandato", de modo que en dicha mayoría no computarían estos concejales.

Con este planteamiento la controversia se resolvió en primera instancia ante el Juzgado de lo Contencioso-Administrativo núm. 4 de Santa Cruz de Tenerife, en fecha 5 de febrero de 2014.

El juzgado interpretó que era causa de transfuguismo, la pérdida de la condición de miembro de un partido político debida a una expulsión por razones disciplinarias derivadas de la ruptura de la disciplina de partido, sin que la dicción legal "haya dejado de 
pertenecer por cualquier causa", que exige el párrafo tercero del art. 197.1 a) LOREG, pueda reducirse a supuestos de abandono voluntario del grupo político.

Al considerar de aplicación el art. 73.3 LBRL y, en consecuencia, la pérdida de adscripción de los concejales expulsados al Grupo Municipal Socialista, resultaría de aplicación el párrafo tercero del art. 197.1 a) LOREG, por lo que la propuesta de moción de censura debía ser apoyada por la mayoría absoluta del número legal de miembros de la Corporación pero incrementada en el mismo número de concejales que los que dejaron de pertenecer al Grupo Municipal Socialista. Por todo lo cual acogió la pretensión de la parte actora, declaró vulnerado el art. 23.2 CE y anuló los Acuerdos de 22 de octubre de 2013, con reconocimiento del derecho del recurrente a ser restablecido en el cargo de Alcalde-Presidente del Ayuntamiento de Tacoronte.

Los cinco concejales expulsados del PSOE interpusieron recurso de apelación contra la Sentencia de 5 de febrero de 2014 ante el Tribunal Superior de Justicia de Canarias quién consideró necesario plantear la cuestión de inconstitucionalidad ante el Tribunal Constitucional.

\section{EL DERECHO A LA PARTICIPACIÓN POLÍTICA}

El planteamiento ante el que se encuentra el Tribunal Constitucional aborda un problema de profundo calado, que se expresa en la disyuntiva entre dos extremos: el derecho a la participación política del concejal electo en las elecciones locales, de la persona en si misma considerada representante de los ciudadanos, por una parte, pero, por otra parte, en la lógica de una democracia representativa, como la nuestra, los partidos políticos establecen en sus listas al perfil de candidatos que se acomodan a su ideario y conforme al cual, el ciudadano expresa su voluntad al manifestar su voto eligiendo al representante del partido como su representante político3.

Hoy día, el colectivo de representantes, por sí mismos considerados, no viene a agrupar a los intereses de la sociedad diseminados con la opinión individual de cada ciudadano.

La labor de representar intereses sociales ha venido a ser ocupada por los partidos políticos. De manera que los representantes serían representantes de ideas, de percepciones de la sociedad, de cómo es o cómo se quiere que sea esa sociedad.

Sin embargo, la sociedad no elige a los partidos como representantes del pueblo. El partido político no es sino el instrumento, como se deduce del art. 6 de la Constitución Es-

${ }^{3}$ Cfr. Cfr. FRANCESC De CARRERAS SERRA, Los partidos en nuestra democracia de partidos, Revista Español de Derecho Constitucional, año 25, Núm. 70, Enero-abril, 2004, pág. 95. 
pañola, el cauce a través del cual el ciudadano, en ejercicio de su soberanía, es conocedor (o debiera serlo) de los intereses perseguidos por todos los miembros de ese partido.

El derecho de sufragio pasivo, que ostentan los candidatos a ocupar cargos públicos, a través de la Teoría de la democracia representativa y de la dinámica de funcionamiento de los partidos políticos, encaja o debe encajar en el ideario defendido por el partido, que aparece a la cabeza como buque insignia de la percepción que su grupo tiene de la realidad y que no es sino el argumento que debiera llevar al elector al depósito de su voto en apoyo de uno u otro grupo4.

En esa disyuntiva planteada resulta imprescindible resaltar que la opción del Constituyente ha sido resaltar el derecho a la participación política como derecho fundamental, elevado al máximo nivel en nuestro Texto Fundamental5.

Desde esa perspectiva el Tribunal Constitucional parte de analizar el contexto que permite identificar el derecho a la participación política contemplado en el artículo 23.2 de la Constitución, diferenciando una dimensión pasiva del derecho de participación política, reconociendo de forma expresa el derecho de los ciudadanos a acceder en condiciones de igualdad a las funciones y cargos públicos con los requisitos que señalen las leyes y también se reconoce, de forma implícita, un derecho a permanecer, en condiciones de igualdad y con los requisitos que señalen las leyes, en los cargos o funciones públicas a los que se accedió ${ }^{6}$, no pudiendo ser removido el cargo electo de los mismos si no es por causas y de acuerdo con procedimientos legalmente establecidos (STC 10/1983, de 21 de febrero, FJ 2).

En segundo lugar, el derecho a la participación política supone un derecho al ejercicio o desempeño del cargo público representativo conforme a lo previsto en las leyes (por ejemplo, STC 246/2012, de 20 de diciembre, FJ 2).

Finalmente, también se reconoce en el derecho a la participación política una garantía de su perfeccionamiento en condiciones de igualdad y de acuerdo con los requisitos que señalen las leyes (por todas, STC 298/2006, de 23 de octubre, FJ 6).

\footnotetext{
${ }^{4}$ Sobre la problemática de los partidos políticos y su encaje en la Teoría de la representación política vid. PEREZ GALVEZ, J. F., LA CREACION DE PARTIDOS POLITICOS EN ESPAÑA, Revista digital de Derecho Administrativo, Núm. 6, 2 semestre 2011 pp. 123 a 161. También en PÉREZ ROYO, J. Curso de derecho constitucional, Marcial Pons, 1999.

${ }^{5}$ Vid CANOSA USERA, R. Sinopsis del Art 23 CE, 2003. Disponible en: http://www.congreso.es/consti/constitucion/indice/sinopsis/sinopsis.jsp?art=23\&tipo=2

${ }^{6}$ Vid. STC 5/1983, de 4 de febrero, FJ 3
} 
Sin embargo, no puede ser considerado un derecho absoluto (ninguno lo es) y la protección constitucional del derecho sólo debe alcanzar al "núcleo de su función representativa"'.

Se ha interpretado, pues, por el Tribunal constitucional, que quedan dentro del núcleo de la función representativa aquellas funciones que solo pueden ejercer los titulares del cargo público por ser la expresión del carácter representativo de la institución (STC 169/2009, de 9 de julio, FJ 3).

Desde la perspectiva exclusivamente local, formarían parte de ese conjunto de funciones las de participar en la actividad de control del gobierno local y en las deliberaciones del Pleno de la corporación; votar en los asuntos sometidos a este órgano; obtener la información necesaria para poder ejercer las facultades anteriores y, por último, participar en las comisiones informativas (por enunciarlas en su integridad, STC 246/2012, de 20 de diciembre, FJ 7).

Parece, pues, desde esta perspectiva, inherente al núcleo de la función representativa el participar en la actividad de control del gobierno local, cuya máxima expresión se concentra en la posibilidad de plantear una moción de censura.

La problemática, expuesto el alcance en el que se debe comprender el derecho a la participación pública, es la limitación que exige el artículo 197.1.e), en la medida en que en el momento inmediatamente anterior a la votación de una moción de censura en el plenario debe satisfacerse el quórum del párrafo segundo de aquella primera letra del artículo 197.1, sin poder computar entre los concejales proponentes de la moción, aquéllos que hayan dejado de pertenecer, por cualquier causa, al grupo político municipal al que se adscribió al inicio de su mandato y no formen o haya formado parte del grupo político municipal al que pertenece el Alcalde cuya censura se propone.

La facultad de promover la moción de censura por los concejales se considera parte del núcleo esencial de la función representativa en el ámbito local, de modo que para los concejales calificados como no adscritos, según la regulación de la Ley 7/1985 reguladora de las bases de régimen local para aquellos que abandonen el grupo de adscripción inicial, la aplicación de la agravación de la mayoría necesaria para que prospere dicha moción supone, evidentemente, una restricción objetiva del margen de iniciativa o impulso de la remoción del Alcalde.

\footnotetext{
${ }^{7}$ Vid. SSTC 141/2007, de 18 de junio, FJ 3; 169/2009, de 9 de julio, FJ 2; 20/2011, de 14 de marzo, FJ 4; $117 / 2012$, de 4 de junio, FJ 3 , o 36/2014, de 27 de febrero. FJ 5.
} 
La cuestión será analizar si la previsión contenida en la reforma operada en 2011 para mitigar el fenómeno del "transfuguismo", no sólo supone una injerencia en un derecho fundamental como es el de participación política, sino si existe una lesión constitucionalmente legítima cuya intensidad implica una vulneración al derecho a la participación política contemplado en el artículo 23.2 de la Constitución.

O bien, por el contrario, si existiría algún fundamento constitucionalmente admisible que respalde tal medida por ser posible su armonización con el perfeccionamiento de la función representativa y la participación política en condiciones de igualdad (STC 298/2006, de 23 de octubre, FJ 6).

\section{EL ALCANCE DE LA MEDIDA “ANTITRANSFUGUISMO”}

La inclusión de la medida antitransfuguismo analizada toma como base la ley 57/2003, de modernización del gobierno local, norma que modificó el artículo 73 de la Ley 7/1985 reguladora de las bases de régimen local e introdujo la figura del concejal no adscrito, que la Jurisprudencia y la doctrina han venido a identificar como aquel concejal que abandona o es expulsado del grupo político o del partido político con el que se presentó a las elecciones.

De este modo se trata de identificar al concejal tránsfuga, que abandona el partido por el que se presentó a las elecciones o el que es expulsado de dicho partido.

Pudiera resultar interesante traer a colación la realidad en el fenómeno tras la entrada en vigor de la modificación de la Ley Orgánica 5/1985 de Régimen electoral general y la controversia que ha tenido en sede judicial8.

En este sentido citaremos que se han presentado mociones de censura bajo el planteamiento citado en 2011en el Cabildo de El Hierro y el Ayuntamiento de Siero, en 2012 en Chinchilla, en 2013 en Coria del Río y el Cabildo de la Palma, hasta 2016, en el ayuntamiento de Victoria de Acentejo, reduciéndose, como vemos, la conflictividad del fenómeno o supuestos puntuales para la escala de municipios que existen en nuestra realidad local.

En el supuesto de el Cabildo de El Hierro se siguió el criterio que en primera instancia se adoptó en el Ayuntamiento de Tacoronte ahora analizado por el Tribunal Constitucional, con la diferencia fundamental de que los Consejeros Insulares de La Palma que fueron expulsados del PSOE, no tuvieron la posibilidad de hacer alegaciones y aportar

\footnotetext{
${ }^{8}$ Una interesante exposición se precisa indiciariamente en la realidad municipal en ESTEBAN ALONSO, J. DE. "El fenómeno Español del transfuguismo político y la jurisprudencia constitucional", Revista de estudios políticos, nº 70, 1990.
} 
prueba en los términos del citado Reglamento del PSOE, ante su expulsión provisional, que no les fue notificada antes de la moción de censura, en consecuencia, en relación a los citados representantes no es posible deducir que hayan abandonado el grupo político, y a estos efectos la efectividad y legalidad de la expulsión del partido político es decisiva, por lo que, en este caso, prosperó la moción presentada.

En el Ayuntamiento de Siero, la moción de censura planteada fue anulada por el Tribunal Superior de Justicia de Asturias, quién consideró que no se reunían los requisitos para la tramitación de la moción de censura por encontrarse cuatro de los concejales proponentes excluidos del Grupo Municipal al que hace referencia el citado artículo 197 de la LOREG. Es decir, no se podría pedir que, una vez suscrita la moción de censura y tramitado el expediente necesario para la expulsión de aquellos que formaban parte del Grupo Municipal del alcalde, no se pueda exigir firmeza en tal resolución, puesto que el breve plazo recogido en la LOREG para la celebración de la sesión sobre la moción de censura (a las 12.00 horas del décimo día hábil siguiente al de su registro) y, en consecuencia, la agravación de la mayoría se debe dar en cualquier caso que se abandone el grupo político de pertenencia, cualquiera que sea su causa, sea voluntaria o por expulsión, a tenor del artículo 73.3 de la Ley 7/1985 reguladora de las bases de régimen local.

En el Ayuntamiento de Chinchilla el Tribunal Superior de Justicia de Castilla la Mancha considera que la moción de censura fue ajustada a derecho, dado que el concejal que permitió que prosperase la moción nunca se integró en la formación política que había apoyado al alcalde, de ahí su condición de no adscrito sin reunir los requisitos para exigir mayoría agravada cuando se planteó la moción de censura.

Por su parte, en el Ayuntamiento de Coria del Río el Tribunal Superior de Justicia de Andalucía desestimó el recurso promovido contra la sentencia que declaraba "ajustada a derecho" la moción de censura aprobada por el pleno de la institución local, en la medida en que no constaba en el expediente el acuerdo de suspensión de militancia por lo que no es posible deducir que quién auspició la moción hubiera abandonado el grupo político de pertenencia.

En el Cabildo de la Palma, La Sala de lo Contencioso Administrativo del Tribunal Superior de Justicia de Canarias desestima el recurso de apelación promovido contra el acuerdo de Pleno que valida la moción de censura en la misma línea que estamos apuntando sobre la imposibilidad de deducir que los representantes hayan abandonado el grupo político de adscripción por su baja provisional en el partido.

En última instancia destacamos, en el Ayuntamiento de Acentejo, en el cual se consideró adecuada a derecho la moción planteada en la medida en que el alcalde censurado ya no pertenecía en el momento de su presentación a ningún grupo municipal por haber sido 
expulsado del partido de adscripción, mientras que los censurantes sí formaban parte de sus partidos políticos y grupos municipales originarios, no dándose las circunstancias para que se exija la agravación de la mayoría en la moción de censura.

\section{LA SENTENCIA DEL TRIBUNAL CONSTITUCIONAL}

El planteamiento del Tribunal Constitucional exige reflexionar, de nuevo en la figura de los concejales no adscritos de los municipios, contemplados por el art. 73.3 LBRL.

Esta figura surge como necesidad de dar respuesta al acuerdo sobre el Código de conducta política en relación con el transfuguismo en las corporaciones locales que se firmó con fecha 7 de julio de 1998 y fue renovado por nuevos acuerdos de 26 de septiembre de 2000 y 23 de mayo de 2006. Como consecuencia del primero de ellos, la Ley 57/2003, de 16 de diciembre, de medidas para la modernización del gobierno local, modificó el art. 73.3 LBRL e introdujo la figura de los miembros de las corporaciones locales no adscritos a ningún grupo político; esto es, los concejales o diputados provinciales que no se integren en el grupo político que constituya la formación electoral por la que fueron elegidos o que abandonen su grupo de procedencia.

Se superaba de ese modo el anterior diseño normativo en el que los miembros de las entidades locales en dicha situación pasaban a integrarse en el grupo mixto

De otra parte, la Ley Orgánica 2/2011, de 28 de enero, por la que se modifica la Ley Orgánica 5/1985, de 19 de junio, del Régimen Electoral General, en su Exposición de motivos conecta previsiones como la cuestionada en el procedimiento constitucional, en ella contenidas, con la anomalía que ha incidido negativamente en el sistema democrático y representativo y que se ha conocido como «transfuguismo».

El Legislador Orgánico interviene, de este modo, sobre la anomalía que el transfuguismo representa, al objeto de asegurar la voluntad popular y la estabilidad de la vida municipal.

Esa lógica de regeneración democrática se concreta en el establecimiento de una restricción en el supuesto de plantear una moción de censura. La restricción obligará a reforzar la mayoría necesaria para que prospere la moción cuando se tome como presupuesto la disolución del nexo con el grupo político municipal de origen; esto es, la separación del grupo político municipal al que se adscribió el concejal al inicio de su mandato9.

\footnotetext{
9 Sobre las consideraciones en relación a los grupos políticos en el ámbito municipal vid. LUCAS VERDÚ, P. "Comentario al artículo 1: Estado social y democrático de derecho", en O. ALZAGA (Direc-
} 
El Tribunal Constitucional analiza la adecuación a la Constitución de la medida propuesta a partir de tres hipótesis.

1.- Si la medida es idónea o adecuada para alcanzar el fin constitucionalmente legítimo perseguido por ella (juicio de idoneidad).

En este sentido, la agravación del derecho de promoción de la moción de censura en el ámbito local, tal y como aparece definida en la norma cuestionada, permite la consecución del fin perseguido "toda vez que el incremento del quorum de iniciativa tiene como efecto derivado el de dificultar la exigencia de responsabilidad política y remoción del Alcalde por quienes les invistieron de la confianza para serlo, entorpeciéndose de ese modo la verificación de cambios que incidan en la estabilidad en la vida municipal y den lugar a la modificación de gobiernos municipales con la participación en el impulso de la moción de censura de concejales que hayan dejado de pertenecer, por cualquier causa, al grupo político municipal al que se adscribieron al inicio de su mandato. Se trata por tanto, en abstracto, de una medida idónea y adecuada para el logro del objetivo que se pretende con su adopción ${ }^{10}$ ".

2.- Si la medida idónea o adecuada es, además, necesaria, en el sentido de que no exista otra medida menos lesiva para la consecución de tal fin con igual eficacia (juicio de necesidad).

El Tribunal Constitucional considera que la medida legal puede también estimarse necesaria al propósito que nace, "puesto que se limita a establecer un reforzamiento del quorum de promoción de la moción de censura sin alterar más allá de ello la dinámica del procedimiento de exigencia de responsabilidad y remoción del Alcalde, como acredita señaladamente que no se altere el régimen de mayorías de la fase de votación, momento en el que los concejales proponentes que hayan dejado de pertenecer, por cualquier causa, al grupo político municipal al que se adscribieron al inicio de su mandato no ven limitado su derecho, conservando la facultad de participar en la votación como cualquier otro concejal. En suma, se persigue dificultar su acción de promoción de la moción para evitar incidencias en la estabilidad en la vida municipal, sin añadir a ello, sin embargo, un escenario de restricción o distorsión abierta de su derecho en la fase de decisión ${ }^{11 ",}$.

tor), Comentarios a la Constitución española de 1978, Tomo I, Madrid: Ed. Cortes Generales y Edersa, 1996.

${ }^{10}$ Cfr. Sentencia del Tribunal Constitucional 151/2017, de 21 de diciembre de 2017. F.J.7 ${ }^{\circ}$.

${ }^{11}$ Ibídem 
3.- Si la medida idónea y menos lesiva resulta ponderada o equilibrada, por derivarse de su aplicación más beneficios o ventajas para el interés general que perjuicios sobre otros bienes o intereses en conflicto (juicio de proporcionalidad en sentido estricto) ${ }^{12}$.

El Tribunal Constitucional establece una precisión obvia pero muy certera al interpretar que la norma impugnada equipara, en la restricción del derecho, a todos los concejales que hayan dejado de pertenecer al grupo político municipal al que se adscribieron al inicio de su mandato. La norma recoge tal extremo estableciendo un rotundo "por cualquier causa".

De este modo, no establece diferencia alguna en función de las circunstancias que puedan haber desencadenado el cese de dicha vinculación con el grupo político municipal, ni precisa el fundamento que permitiría asociar la disolución de la relación orgánica con el grupo político de origen y los fines singulares, relativos a la estabilidad municipal, que la norma debe intentar asegurar, según las declaraciones del Preámbulo de la Ley Orgánica.

En su sentencia se aprecia que la norma "no distingue tampoco, en particular, en función de que la separación del grupo ataña o no a la vida de esa concreta Corporación municipal. Tampoco valora el significado que eventualmente podría revelar la proporción de concejales que hayan expresado el desafecto o desacuerdo con el grupo político. Y no precisa, en fin, las razones que pudieran expresar un fraude de representación, ya sean políticas o de otra índole, y que pudieran estar en la base de ese resultado. Estima, antes bien, que cualquier disolución de ese nexo orgánico (único factor relevante y presupuesto único de la norma) es contraria en sí misma considerada a la estabilidad de la vida municipal o del gobierno local, equiparando el respeto de la voluntad popular y del gobierno local a la protección del Alcalde que fue designado, cuando lo cierto es que la representación política, en democracia, es siempre colegiada y el Alcalde, por ello, representa al ayuntamiento, perfilándose las mayorías de acuerdo a los pactos que se establecen" $"$.

Con esta base, advierte el Tribunal Constitucional que no es constitucionalmente admisible que cualquier hipótesis de disolución del vínculo político sea merecedora de una intervención que restrinja la mayoría necesaria para que prospere la moción de censura, sin previsión normativa que describa el alcance y característica de la disolución de dicho vínculo.

Olvida el legislador, entiende el Tribunal Constitucional, que la aplicación de la norma no solo puede dificultar sino incluso hacer del todo inviable en una pluralidad de esce-

\footnotetext{
${ }^{12}$ Cfr. Sentencia del Tribunal Constitucional, 89/2017, de 4 de julio, F.J.9 ${ }^{\circ}$.

${ }^{13}$ Cfr. Sentencia del Tribunal Constitucional 151/2017, de 21 de diciembre de 2017. F.J.7 ${ }^{\circ}$.
} 
narios la propia tramitación de aquella iniciativa de control del gobierno municipal que representa la moción de censura, vetando la exigencia de responsabilidad y la remoción del Alcalde.

En definitiva, la norma, sujeta al concejal al grupo político de origen bajo advertencia de restricción de las funciones representativas básicas, sin que ese efecto responda inevitablemente a una defraudación de la voluntad popular o a un hacer que busque la desestabilización de la dinámica municipal.

El artículo 23.2 CE, por tanto, resulta violado, porque la legalidad a la que remite es, en este caso, contraria a la Constitución y, en especial, a la naturaleza de la representación política, por lo que debe proceder a declarar su inconstitucionalidad.

\section{CONCLUSIÓN}

La sentencia precisa que, para preservar el principio de seguridad jurídica, la declaración de inconstitucionalidad del párrafo cuestionado no afectará a situaciones jurídicas consolidadas14. Asimismo, la declaración de nulidad no será efectiva hasta la próxima convocatoria de elecciones locales, periodo de tiempo en el que el legislador podrá reformar la norma "observando el contenido de este pronunciamiento".

A propósito de los efectos de la Sentencia, la propia Vicepresidenta del Tribunal discrepa de sus compañeros en este aspecto de posponer la nulidad del precepto recurrido hasta la celebración de nuevas elecciones locales. Retrasar la nulidad de una norma que el Tribunal considera fuera de la Constitución es una solución que, afirma, debe ser "excepcional"; en todo caso, debe responder a la finalidad de "preservar bienes o valores que el Tribunal considera constitucionalmente relevantes y que justifican la desvinculación entre inconstitucionalidad y nulidad" y que el Tribunal Constitucional no menciona.

No es poco controvertida la Sentencia publicada por el Tribunal Constitucional, como se ha evidenciado a través de los votos particulares formulados. En este sentido, el Magis-

\footnotetext{
${ }^{14}$ Sobre el alcance y efectos de las sentencias del Tribunal Constitucional vid. DIAZ REVORIO, F.J., TIPOLOGÍA Y EFECTOS DE LAS SENTENCIAS DEL TRIBUNAL CONSTITUCIONAL EN LOS PROCEDIMIENTOS DE INCONSTITUCIONALIDAD ANTE LA REFORMA DE LA LEY ORGÁNICA DEL TRIBUNAL CONSTITUCIONAL ESPAÑOL, en Pablo Pérez Tremps (coord.), La reforma del Tribunal Constitucional, Tirant lo blanch, Valencia, 2007, págs. 149-175. También en Eduardo Ferrer Mac-Gregor/ Arturo Zaldívar Lelo de Larrea (coords.), La ciencia del Derecho Procesal Constitucional. Estudios en homenaje a Héctor Fix-Zamudio en sus cincuenta años como investigador del derecho, tomo V: Juez y sentencia constitucional, Instituto de Investigaciones Jurídicas, México, 2008, págs. 291-319 (ISBN 978-970-32-5380-7).
} 
trado Conde-Pumpido, a cuyo voto particular se adhieren los Magistrados Xiol y Montoya, considera que la cuestión de inconstitucionalidad debió desestimarse.

Los Magistrados que firman el voto no comparten el análisis de proporcionalidad de la norma que contiene la sentencia porque, explican, "no realiza ponderación alguna de beneficios y perjuicios", como establece la doctrina constitucional. Consideran que la medida declarada inconstitucional es "equilibrada" y que de su aplicación se derivan "más beneficios o ventajas para el interés general que perjuicios sobre otros bienes o intereses en conflicto, incluido el ius in officium de los concejales", analizando el tercero de los aspectos comentados en la sentencia como presupuestos justificativos o no del alcance de la norma.

El voto particular incide en el carácter "legítimo" de la medida, dada la importancia que "para la vida local tiene que se respeten los resultados de los comicios locales"; y resalta la quiebra que, para "la legitimidad del gobierno local y, con ello, del propio sistema democrático" supone el transfuguismo "a los ojos de los ciudadanos".

En tanto el legislador no pueda adoptar otra medida de lucha contra el transfuguismo se plantea un horizonte complejo en el que de nuevo la estabilidad democrática de las Entidades Locales y el fenómeno desterrado del transfuguismo podrá recuperar fuerzas y dar aliento a aquellos cuyos objetivos no son, precisamente, la preservación del interés público y la salvaguarda de la Democracia.

\section{BIBLIOGRAFÍA}

Acuerdo sobre el Código de Conducta Política en relación con el transfuguismo en las Corporaciones Locales, II Addenda, Ministerio de Administraciones Públicas, 2006.

CANOSA USERA, R. Sinopsis del Art 23 CE, 2003. Disponible en: http://www.congreso.es/consti/constitucion/indice/sinopsis/sinopsis.jsp?

DIAZ REVORIO, F.J., TIPOLOGÍA Y EFECTOS DE LAS SENTENCIAS DEL TRIBUNAL CONSTITUCIONAL EN LOS PROCEDIMIENTOS DE INCONSTITUCIONALIDAD ANTE LA REFORMA DE LA LEY ORGÁNICA DEL TRIBUNAL CONSTITUCIONAL ESPAÑOL, en Pablo Pérez Tremps (coord.), La reforma del Tribunal Constitucional, Tirant lo blanch, Valencia, 2007.

ESTEBAN ALONSO, J. DE. "El fenómeno Español del transfugismo político y la jurisprudencia constitucional”, Revista de estudios políticos, nº 70, 1990. 
FRANCESC De CARRERAS SERRA, "Los partidos en nuestra democracia de partidos", Revista Española de Derecho Constitucional, año 25, Núm. 70, Enero-abril, 2004.

MAC GREGOR F., ZALDÍVAR LELO DE LARREA, A. (coords.), La ciencia del Derecho Procesal Constitucional. Estudios en homenaje a Héctor Fix-Zamudio en sus cincuenta años como investigador del derecho, tomo V: Juez y sentencia constitucional, Instituto de Investigaciones Jurídicas, México, 2008.

LUCAS VERDÚ, P. "Comentario al artículo 1: Estado social y democrático de derecho", en O. ALZAGA (Director), Comentarios a la Constitución española de 1978, Tomo I, Madrid: Ed. Cortes Generales y Edersa, 1996

PÉREZ ROYO, J. Curso de derecho constitucional, Marcial Pons, 1999

PEREZ GALVEZ, J. F., "La creación de partidos políticos en España”, Revista digital de Derecho Administrativo, Núm. 6, 2 semestre 2011.

SÁNCHEZ GONZÁLEZ, J.F., El juego de la democracia. El Consultor de los Ayuntamientos y juazgados, $\mathrm{N}^{\circ}$ 8, Sección Colaboraciones, Quincena del 30 Abr. al 14 May. 2011.

\section{JURISPRUDENCIA}

S.T.C 151/2017, de 21 de diciembre

S.T.C. 89/2017, de 4 de julio

S.T.C. 141/2007, de 18 de junio

S.T.C. 169/2009, de 9 de julio

S.T.C. 20/2011, de 14 de marzo

S.T.C. $117 / 2012$, de 4 de junio

S.T.C. 36/2014, de 27 de febrero

STC 5/1983, de 4 de febrero 